Energy Research Journal 1 (2): 55-61, 2010

ISSN 1949-0151

(C) 2010 Science Publications

\title{
Sliding Mode Control with PID Tuning Technique: An Application to a DC Servo Motor Position Tracking Control
}

\author{
${ }^{1}$ Tossaporn Chamsai, ${ }^{2}$ Piyoros Jirawattana and ${ }^{1}$ Thana Radpukdee \\ ${ }^{1}$ Department of Industrial Engineering, \\ ${ }^{2}$ Department of Mechanical Engineering, \\ Khon Kaen University, Khon Kaen, Thailand 40002
}

\begin{abstract}
Problem statement: In this study, a combination of a classical Sliding Mode Control (SMC) and a PID tuning technique with low-pass filter is developed for a position tracking control of a DC servo motor. Approach: The DC servo motor will be used to adjust the throttle angle of the gasoline engine in our laboratory. To control the engine speed to be accurate, the servo motor position has to be controlled precisely. Results: Uncertainty and nonlinearity of the servo motor system can be surmounted by the sliding mode control while the system response can be fine adjusted via the PID gain tuning. A low-pass filter has been incorporated also in order to eliminate and limit amplification of noise due to differentiation in the PID algorithm. The stability of the control system is guaranteed by the Lyapunov stability theorem. The experimental results shown that, the proposed technique has good tracking performance compares to a PIDSMC and a conventional PID technique even without actuator model. Conclusion/Recommendations: However, the performance strongly depends on the specified control gain in PID portion and sliding function. Therefore, any self tuning control gain techniques should be developed further.
\end{abstract}

Key words: PID control, sliding mode control, DC servo motor

\section{INTRODUCTION}

Recently, DC servo motors have been widely used as an actuator for motion control and direct-drive applications. Examples are as robotic and actuator for automation process, mechanical motion and others. This is because the well controllability features of the DC servo motors and they have adaptability to various types of control methods. The DC servo motors have been extensively applying in many servomechanisms. Therefore, it is very important to study about the position control of the DC servo motors.

Generally, the DC servo motor systems have uncertain and nonlinear characteristics which degrade performance of controllers. Based on these reasons, Sliding Mode Control (SMC) is one of the popular control strategies and powerful control technology to deal with the nonlinear uncertain system (Utkin, 1978). It is often used to handle any worst-case control environment such as parametric perturbations with lower and upper bounds, external disturbances, stickslip friction and etc. Precise dynamic models are not required and its control algorithms can be easily implemented. Moreover, its advantage is good robustness. However, the robustness of the sliding control strongly depends on specified parameters in designing of the sliding function (Fujisawa and Kawada, 2004).

To improve ability to tuning of the sliding mode control, some means of control technique has to be added. One of the most useful control algorithm in linear and nonlinear control systems is PID control (Kelly and Moreno, 2001). It is extensively interested to tune control gain by PID method. The popularity of PID controllers is due to their functional simplicity and reliability (Moradi, 2003). The PID control tuning was proposed for a class of uncertain chaotic systems with external disturbance (Chang and Yan, 2005). The major concern of the PID tuning is its transient behaviors either in the time domain, such as peak of overshoot, rise time and setting time or in frequency domain such as bandwidth, damping ratio and undamped natural frequency (Xu and Huang, 2007).

In this study, the PID control based on sliding surface with a low-pass filter has been adopted to control the motion of a DC servo motor to achieve the desired position tracking performance. The goal is to achieve robustness of the servo motor system in order to against system parameter variations and any external

Corresponding Author: Thana Radpukdee, Department of Industrial Engineering, Khon Kaen University, Khon Kaen, Thailand 40002 Tel: +(66) 43343117 
disturbances. This study will present the system description and the proposed control technique design. Stability analysis of the proposed control technique was derived in stability analysis. The comparisons of the proposed technique with a conventional PID and a PIDSMC controllers that demonstrated faster response, more robustness to parameter variations and external disturbances of the proposed controller than the other controllers will be presented in results. Then conclusion will be given.

System description and definition: An uncer-tain dynamic system satisfying the matching condition (Barmish and Leitmann, 1982) can be described by canonical form as below:

$x^{(n)}(t)=f_{n}(X, t)+B_{n}(X, t) u_{n}(t)+B_{n}(X, t) \eta_{n}(X, t)$

$\mathrm{x}\left(\mathrm{t}_{0}\right)=\mathrm{x}_{0}$

where, $\quad \mathrm{x}^{(\mathrm{n})}(\mathrm{t})=\left[\mathrm{x}_{1}^{(\mathrm{n} 1)}, \mathrm{x}_{2}^{(\mathrm{n} 2)}, \ldots, \mathrm{x}_{\mathrm{m}}^{(\mathrm{nm})}\right]^{\mathrm{T}} \in \mathrm{R}^{\mathrm{m}}, \mathrm{x}_{\mathrm{i}}^{(\mathrm{ni})} \in \mathrm{R}, \mathrm{i}=$ $1,2, \ldots, \mathrm{m}$ in which $\mathrm{x}_{\mathrm{i}}^{(\mathrm{k})}=\mathrm{d}^{\mathrm{k}}\left(\mathrm{x}_{\mathrm{i}}\right) / \mathrm{dt}$ is the highest order

of the state vector, $t \in R$ is time, $X_{i}=\left[x_{i}, \dot{x}_{i}, \ldots, x_{i}^{(n i-1)}\right]^{T}$ $\in \mathrm{R}^{\mathrm{ni}}$ is the state subvector for the nonlinear square system that forms the global state vector $\mathrm{X}=$ $\left\lfloor X_{1}^{T}, \ldots, X_{m}^{T}\right\rfloor^{T} \in R^{r}, \quad r=\sum_{i=1}^{M} n_{i}, \quad m$ is the number of independent coordinates of $\mathrm{X}_{\mathrm{i}}$ that are assumed to be available for feedback without noise, the subscript $(.)_{n}$ stands for belonging to the n-order system, $\mathrm{u}_{\mathrm{n}}(\mathrm{t})=$ $\left[\mathrm{u}_{1}, \ldots, \mathrm{u}_{\mathrm{m}}\right]^{\mathrm{T}} \in \mathrm{R}^{\mathrm{m}}$ is the control input, $\eta_{\mathrm{n}}(\mathrm{X}, \mathrm{t})=$ $\left[\eta_{1}, \ldots, \eta_{m}\right]^{T} \in R^{m}$ is the uncertain element that forms the lump uncertain element $\mathrm{B}_{\mathrm{n}}(\mathrm{X}, \mathrm{t}) \eta_{\mathrm{n}}(\mathrm{X}, \mathrm{t})$ that enters only the highest order of the system, $\mathrm{f}_{\mathrm{n}}(\mathrm{X}, \mathrm{t})=\left[\mathrm{f}_{1}, \ldots, \mathrm{f}_{\mathrm{m}}\right]^{\mathrm{T}} \in$ $\mathrm{R}^{\mathrm{m}}$ is the known nonlinear function and $\mathrm{B}_{\mathrm{n}}(\mathrm{X}, \mathrm{t})=\left[\mathrm{b}_{\mathrm{ij}}\right]$ $\in \mathrm{R}^{\mathrm{mxm}}, \mathrm{i}, \mathrm{j}=1, \ldots, \mathrm{m}$ is the known control gain distribution matrix.

For the system satisfying the matching conditions under consideration, the system uncertainty is required to lie in the image of the known control gain distribution matrix $\mathrm{B}_{\mathrm{n}}(\mathrm{X}, \mathrm{t})$ (Decarlo et al., 1988). Therefore, the total uncertainty can be lumped into the single uncertain element $\eta_{\mathrm{n}}(\mathrm{X}, \mathrm{t})$ and the control input must have more influence over the system dynamic than the uncertainty (Barmish and Leitmann, 1982). However, for simplicity, only the first order $\left(\right.$ all $\left.n_{i}=1\right)$ of Eq. 1 will be considered. Thus, the system equation can be rewritten as:

$$
\begin{aligned}
& \dot{x}(t)=f(X, t)+B(X, t) u(t)+B(X, t) \eta(X, t) \\
& x\left(t_{0}\right)=x_{0}
\end{aligned}
$$

A control task is to make the system state $\mathrm{x}_{\mathrm{i}}(\mathrm{t})$ to track the desired trajectory $\mathrm{x}_{\mathrm{id}}(\mathrm{t})$ so that the error $\tilde{x}_{\mathrm{i}}=\mathrm{x}_{\mathrm{i}}(\mathrm{t})-\mathrm{x}_{\mathrm{id}}(\mathrm{t}) \rightarrow 0, \mathrm{i}=1, \ldots, \mathrm{m}$. Note that the subscript (.) $)_{\mathrm{n}}$ is not present in this case and if there is no uncertainty, the last term on the Right-Hand Side (RHS) of Eq. 2 will disappear. By considering Eq. 2 the uniform ultimate boundedness can be achieved due to the knowledge of the maximum possible value of the norm $\|\mathrm{B}(\mathrm{X}, \mathrm{t}) \eta(\mathrm{X}, \mathrm{t})\|$ (Corless and Leitmann, 1981). However, if the uncertain element can be realized, the control law can be designed. Therefore, with the following assumption, the next discussion will describe the technique to against system uncertainty using the first derivative of the sliding function for the matching system (Radpukdee and Jirawattana, 2008). Then, a controller design and a stability analysis based on Lyapunov's second method will be presented:

- Assumption I: The functions $\mathrm{f}(\mathrm{X}, \mathrm{t}), \mathrm{B}(\mathrm{X}, \mathrm{t})$ and $\eta(X, t)$ are continuous in $X$ for all $t$. They are all Lebesgue measurable in $\mathrm{t}$ (Coddington and Levison, 1984)

- Assumption II: The lumped uncertain element is bounded and the maximum possible value of its norm $\|\mathrm{B}(\mathrm{X}, \mathrm{t}) \eta(\mathrm{X}, \mathrm{t})\|$ is known

- Assumption III: The functions $\mathrm{f}(\mathrm{X}, \mathrm{t}), \mathrm{B}(\mathrm{X}, \mathrm{t})$, and $\eta(X, t)$ are bounded by a Lebesgue integrable function of $\mathrm{t}$

- Assumption IV: The desired dynamic function is bounded and $\mathrm{C}^{\infty}$ class so that the trajectory $\mathrm{x}_{\mathrm{d}}(\mathrm{t})$ is smooth and continuous for all $\mathrm{t}$

Controller design: The proposed of controller is described. The definition of the classical sliding mode control also recalled. Then a control law will be determine in order to force the system to reach and stay on a sliding surface $\left(\mathrm{s}_{\mathrm{t}}(\mathrm{x})=0\right)$. In the stability analysis, asymptotic stability of the proposed control system of Eq. 2 has been evaluated by Lyapunov stability theorem.

Let $\mathrm{s}_{\mathrm{t}}(\mathrm{x})=0$ be the sliding surface which is expected to response desired control specifications. It is refers to the definition of the sliding function (Slotine and $\mathrm{Li}, 1991$ ). The sliding function can be defined individually on each sliding surface as:

$\mathrm{s}_{\mathrm{it}}\left(\mathrm{x}_{\mathrm{i}}(\mathrm{t})\right)=\left(\frac{\mathrm{d}}{\mathrm{dt}}+\lambda_{\mathrm{i}}\right)^{\mathrm{n}_{\mathrm{i}}-1} \tilde{\mathrm{x}}_{\mathrm{i}}, \mathrm{i}=1, \ldots, \mathrm{m}$

Where:

$\lambda_{\mathrm{i}}=$ A strictly positive constant

$\mathrm{n}_{\mathrm{i}}=$ The order of the system of interest

Note that Eq. 3 is continuous in $\tilde{x}_{i}$ for all $t$, so it has a unique solution on the sliding surface $s_{i t}=0$. 
To make the control input and uncertain elements within the range space of the input distribution matrix $\mathrm{B}(\mathrm{X}, \mathrm{t})$ to appear, the first derivative of the sliding function of Eq. 3 for the $n_{i}$ order system (higher than one) can be calculated from:

$\dot{\mathrm{s}}_{\mathrm{it}}=\sum_{\mathrm{k}=0}^{\mathrm{n}_{\mathrm{i}}-1} \frac{\partial \mathrm{s}_{\mathrm{it}}}{\partial \tilde{\mathrm{x}}^{(k)}} \tilde{\mathrm{x}}_{\mathrm{i}}^{(\mathrm{k})}=\frac{\partial \mathrm{s}_{\mathrm{it}}}{\partial \tilde{\mathrm{x}}^{\left(\mathrm{n}_{\mathrm{i}}-1\right)}} \tilde{\mathrm{x}}_{\mathrm{i}}^{\left(\mathrm{n}_{\mathrm{i}}-1\right)}+\sum_{\mathrm{k}=1}^{\mathrm{n}_{\mathrm{i}}-2} \frac{\partial \mathrm{s}_{\mathrm{it}}}{\partial \tilde{\mathrm{x}}_{\mathrm{i}}\left({ }^{(k)}\right.} \tilde{\mathrm{x}}_{\mathrm{ki}}^{(\mathrm{k})}$

with

$\tilde{\mathrm{x}}_{\mathrm{i}}^{(\mathrm{k})}=\frac{\mathrm{d}^{\mathrm{k}}\left(\tilde{\mathrm{x}}_{\mathrm{x}}\right)}{\mathrm{dt}^{\mathrm{k}}}$

where, the superscript $\mathrm{k}=1, \ldots, \mathrm{n}_{\mathrm{i}}-1$ is the order of an error derivative.

To derive the control law, some of the basic concepts of the classical sliding mode control should be given and considered on the system with exactly known dynamics (Eq. 2 without any imperfection) and the sliding function is presented in term of the first order as Eq. 6, from Eq. 3 the sliding function is:

$$
\mathrm{s}=\mathrm{x}-\mathrm{x}_{\mathrm{d}}
$$

Then the first order derivative of an error $\left(\mathrm{x}-\mathrm{x}_{\mathrm{d}}\right)$ in Eq. 5 is:

$\dot{\mathrm{s}}_{\mathrm{t}}(\mathrm{x})=\mathrm{C}\left(\dot{\mathrm{x}}-\dot{\mathrm{x}}_{\mathrm{d}}\right)$

The best approximation of an equivalent control $\left(\mathrm{u}_{\mathrm{eq}}\right)$ is found from Eq. 7 with $\dot{\mathrm{s}}=0$ that is:

$\mathrm{Cf}+\mathrm{CBu}_{\mathrm{eq}}-\mathrm{C} \dot{\mathrm{x}}_{\mathrm{d}}=0$

where, $\mathrm{C}$ is a positive constant coefficient $\mathrm{m} \times \mathrm{m}$ matrix. It is linearly independent in full row rank and its arguments equal to 1 , which implies that det $|\mathrm{CB}| \neq 0$ for any $\mathrm{x}$ and $\mathrm{t}$ (Utkin, 1978). Then, the equivalent control law can be rearranged as:

$\mathrm{u}_{\mathrm{eq}}=(\mathrm{CB})^{-1}\left(-\mathrm{Cf}+\mathrm{C}_{\mathrm{d}}\right)$

Then the position tracking problem can be considered as the error remaining on the sliding surface $\mathrm{s}(\mathrm{t}) \neq 0$ for all $\mathrm{t} \geq 0$. If the system trajectory has reached to the sliding surface $s(t)=0$, it implies that the control law can force the error $\mathrm{e}(\mathrm{t})$ to approach the sliding surface and then move along the sliding surface. Therefore it is required that the sliding surface must be stable, which means $\lim _{\mathrm{t} \rightarrow \infty} \mathrm{e}(\mathrm{t})=0$, then the error will be asymptotically. This implies that response of the system will track the desired trajectory asymptotically (Slotine and $\mathrm{Li}, 1991$ ).

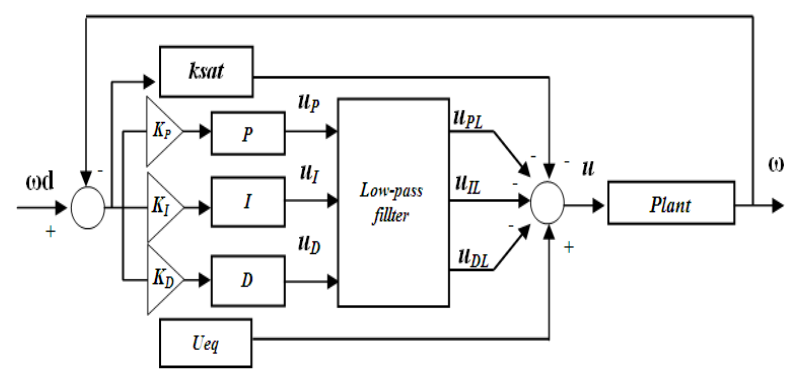

Fig. 1: Schematic diagram of PIDSMC with an adopted low-pass filter

Practically in the sliding mode, the equivalent control input (Eq. 8) is described when the trajectory is nearly $\mathrm{s}(\mathrm{t})=0$ (Jafarov et al., 2005), while the PID control is determined when $\mathrm{s}(\mathrm{t}) \neq 0$ (Jafarov et al., 2005). Refers to the PID illustrated in Fig. 1, given the coefficients $\mathrm{K}_{\mathrm{P}}, \mathrm{K}_{\mathrm{I}}, \mathrm{K}_{\mathrm{D}} \in \mathrm{R}^{+}$are strictly positive constants and lets the tracking error in a closed loop control system to be "e". If the control gain $\mathrm{K}_{\mathrm{P}}, \mathrm{K}_{\mathrm{I}}, \mathrm{K}_{\mathrm{D}}$ are properly chosen, it implies that $\lim _{t \rightarrow \infty} \mathrm{e}=0$ and it means the closed-loop system is globally asymptotically stable (Wai et al., 2004). The error "e" can be defined in terms of physical plant parameter as:

$\mathrm{e}=\omega-\omega_{\mathrm{d}}$

Where

$\omega_{\mathrm{d}}=$ The desired signal

$\omega=$ The output signal (angular displacement) from the measurement of a plant

Intuitively, the error in PID and sliding mode function are similar, except that the sliding function can take all error dynamics (errors derivative) into account. Therefore, any imperfection occurred in systems due to the PID could be coped by the sliding control.

The imperfection can be explained as follow. The initial state response of the PID controlled system such that the transient behaviors such as peak of overshoot, rise time, setting time which occurs from the designing parameters in the PID controller are not suitable. Thus, it remains the errors on the controlled system. However, these can be reduced by adopted low-pass filter to the PID controller.

As stated earlier, the sliding control can improve the PID control, The proposed control algorithm would be sliding mode control with PID controller gather with the low-pass filter as illustrated in Fig. 1, thus the control inputs $\mathrm{u}_{\mathrm{IL}}, \mathrm{u}_{\mathrm{PL}}, \mathrm{u}_{\mathrm{DL}}$ can be written as:

$$
u_{I L}(t)=\int_{0}^{t} u_{I}(T) e^{-x} d T
$$


$u_{P L}(t)=\int_{0}^{t} u_{P}(T) e^{-\gamma} d T$

$$
u_{D L}(t)=\int_{0}^{t} u_{D}(T) e^{-\gamma t} d T
$$

Where:

$\gamma=$ A low-pass filter frequency

$\mathrm{T}=$ Time

Thus, to satisfy the reaching condition, the control input based PID tuning with sliding mode control can be derived in term of the control input $u$ as Eq. 13, Then argument " $\mathrm{t}$ " is omitted for simplicity from now on.

$\mathrm{u}=\mathrm{u}_{\mathrm{eq}}-(\mathrm{CB})^{-1}\left(\mathrm{u}_{\mathrm{DL}}+\mathrm{u}_{\mathrm{IL}}+\mathrm{u}_{\mathrm{PL}}\right)$

From Eq. 13 it can be rearranged as:

$$
\mathrm{u}=(\mathrm{CB})^{-1}\left[-\mathrm{Cf}+\mathrm{C}_{\mathrm{d}}-\mathrm{u}_{\mathrm{DL}}-\mathrm{u}_{\mathrm{IL}}-\mathrm{u}_{\mathrm{PL}}\right]
$$

In order to eliminate the imperfection of the PID and the well known chattering phenomenon, which may occur from switching action of SMC. The continuous control function would be chosen as in the work of Slotine and Li (1991). Thus the control input from Eq. 14 can be rewritten as:

$\mathrm{u}=\mathrm{u}_{\mathrm{eq}}-(\mathrm{CB})^{-1}\left(\mathrm{u}_{\mathrm{DL}}+\mathrm{u}_{\mathrm{IL}}+\mathrm{u}_{\mathrm{PL}}\right)-(\mathrm{CB})^{-1} \mathrm{ksat}(\mathrm{Y})$

or

$$
\mathrm{u}=(\mathrm{CB})^{-1}\left[-\mathrm{Cf}+\mathrm{C} \dot{\mathrm{x}}_{\mathrm{d}}-\left(\mathrm{u}_{\mathrm{DL}}+\mathrm{u}_{\mathrm{IL}}+\mathrm{u}_{\mathrm{PL}}\right)-\operatorname{ksat}(\mathrm{y})\right]
$$

The schematic diagram of the proposed control law from Eq. 16 was shown in Fig. 1 and then $\mathrm{Y}$ in the last term of RHS of Eq.16 is a vector whose components are $\mathrm{y}_{\mathrm{i}}=\mathrm{s}_{\mathrm{i}} / \Phi_{\mathrm{i}}$ and $\Phi_{\mathrm{i}}$ is the boundary layer width, $\mathrm{k}$ is positive constants, $\mathrm{k} \in \mathrm{R}^{+}$. such that:

$$
\operatorname{sat}\left(Y_{i}\right)=\left\{\begin{array}{llr}
y_{i} & \text { if } & \left|y_{i}\right| \leq 1 \\
\operatorname{sgn}\left(y_{i}\right) & \text { if } & \text { otherwise }
\end{array}\right.
$$

where

$$
\operatorname{sgn}\left(s_{i}\right)=\left\{\begin{array}{lll}
+1 & \text { if } & s_{i}>0 \\
-1 & \text { if } & s_{i}<0
\end{array}\right.
$$

Then the initial output trajectory is not on the sliding surface $s(t)$, the controller should be designed such that it can drive the output trajectory into the sliding surface $s(t)=0$. The output trajectory, under the condition that it will move toward and reach the sliding surface, is said to be on the reaching phase.

Stability analysis: The Lyapunov theorem has been chosen to prove the stability of the proposed control system that the error response asymptotically convergences to the sliding surface if the control law $u$ is constructed to satisfy the condition of $\mathrm{s}^{\mathrm{T}} \dot{\mathrm{s}} \leq 0$. Lets the Lyapunov function candidate as:

$\mathrm{V}=\frac{1}{2} \mathrm{~s}^{\mathrm{T}} \mathrm{S}$

With time differentiation to yield

$\dot{\mathrm{V}}=\mathrm{s}^{\mathrm{T}} \dot{\mathrm{S}}$

From Eq. 1 and 6, where $\dot{\mathrm{s}}=\dot{\mathrm{x}}-\dot{\mathrm{x}}_{\mathrm{d}}$, thus:

$$
\begin{aligned}
\dot{\mathrm{V}}= & \mathrm{s}^{\mathrm{T}} \mathrm{C}\left[\mathrm{f}+\mathrm{B}\left(( \mathrm { CB } ) ^ { - 1 } \left(-\mathrm{Cf}+\mathrm{C} \dot{\mathrm{x}}_{\mathrm{d}}-\left(\mathrm{u}_{\mathrm{DL}}-\right.\right.\right.\right. \\
& \left.\left.\left.\mathrm{u}_{\mathrm{IL}}-\mathrm{u}_{\mathrm{PL}}\right)-\mathrm{ksat}(\mathrm{Y})\right)+\mathrm{CB} \eta-\dot{\mathrm{x}}_{\mathrm{d}}\right] \\
= & \mathrm{s}^{\mathrm{T}}\left[-\left(\mathrm{u}_{\mathrm{DL}}+\mathrm{u}_{\mathrm{IL}}+\mathrm{u}_{\mathrm{PL}}\right)-\operatorname{ksat}(\mathrm{Y})+\mathrm{CB \eta}\right] \\
\mathrm{S}^{\mathrm{T}} \mathrm{S}= & -\mathrm{s}^{\mathrm{T}} \mathrm{ksat}(\mathrm{Y})+\mathrm{CB \eta}-\left(\mathrm{u}_{\mathrm{DL}}+\mathrm{u}_{\mathrm{IL}}+\mathrm{u}_{\mathrm{PL}}\right) \\
& \dot{\mathrm{V}} \leq 0
\end{aligned}
$$

From Eq. 16, since the assumptions I-IV are satisfied and available global state vector $\mathrm{x} \in \mathrm{R}^{\mathrm{m}}$ has no disturbances, the asymptotic stability of the error response along sliding surface from the control law in Eq. 16 can be guarantee as long as $\dot{V} \leq 0$. In this case, when $\left\|\mathrm{s}^{\mathrm{T}} \mathrm{ksat}(\mathrm{Y})\right\| \geq\left\|\mathrm{CB} \eta-\left(\mathrm{u}_{\mathrm{DL}}+\mathrm{u}_{\mathrm{IL}}+\mathrm{u}_{\mathrm{PL}}\right)\right\|$ Additionally, the continuous term $\operatorname{ksat}(\mathrm{Y})$ has been selected commonly as in SMC problems to avoid chattering of the control force and to achieve stability.

Consequently, the desired response depends on the selection of the constants $\mathrm{K}_{\mathrm{P}}, \mathrm{K}_{\mathrm{I}}, \mathrm{K}_{\mathrm{D}}$ and $\mathrm{k}$ which have to be suitable from experimental adjustment.

\section{MATERIAL AND METHODS}

According to the schematic diagram of the experimental setup in Fig. 1, the propose of controller is to control the angular movable of a de servo motor via MATLAB-simulink programming and the implementation of there technique is shown in Fig. 2. 
DC supply 1 is supply voltage to potentiometer about $6.5 \mathrm{~V}$. which using for notify the position of de servo motor and the power-amp able to generate the current(current of PWM signal) about $80 \mathrm{~mA}$ for supply to signal-control line of dc servo motor. DC supply 2 using for supply voltage to VCC-line of DC servo motor. The signal control directed to the power-amp via DAC card which it generated by algorithm of controller by MATLAB-simulink programming. The simplified block diagram for implementation shown in Fig. 3 and from Fig. 1 based on Eq. 2 can be simplified all parameters as in Table 1.

Then the low-pass filter can be as $\frac{100}{\mathrm{~s}+200}$.

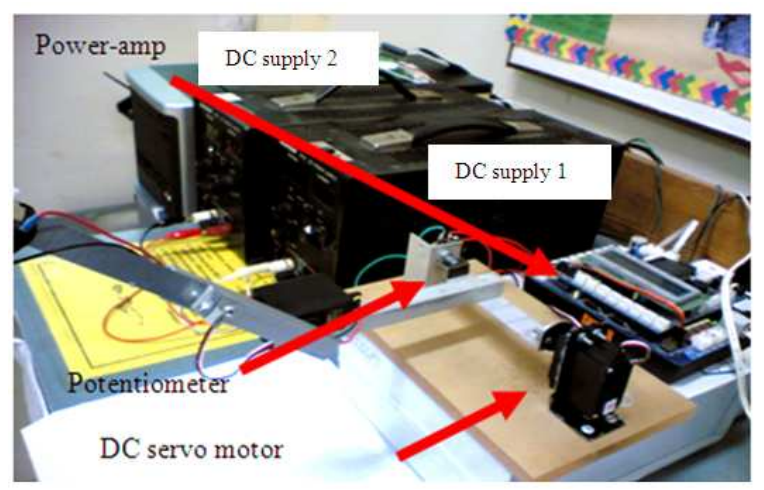

Fig. 2: Implementation for the angular displacement control of the DC servo motor

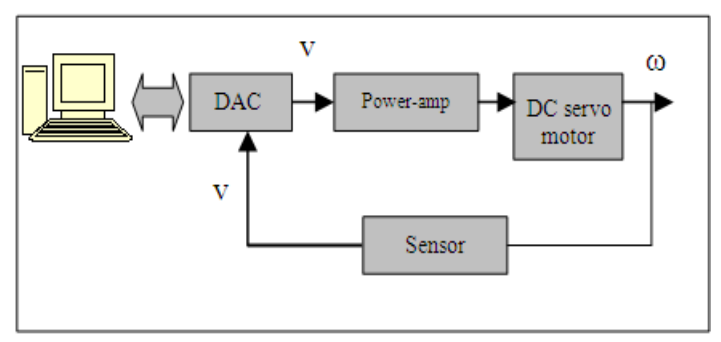

Fig. 3: Block diagram structure for the angular displacement control of the DC servo motor

Table 1: Parameters for implementation

Implement constant

PID with SMC (propose technique) PID (conventional)

\begin{tabular}{lrr} 
& & \\
$\mathrm{k}$ & 2000 & - \\
$\mathrm{K}_{\mathrm{P}}$ & 30 & 30 \\
$\mathrm{~K}_{\mathrm{l}}$ & 450 & 450 \\
$\mathrm{~K}_{\mathrm{D}}$ & 1 & 1 \\
$\Phi$ & 20 & - \\
\hline
\end{tabular}

\section{RESULTS AND DISCUSSION}

Some experimental results are provided here to demonstrate the performance of the proposed technique. Figure 4 shows the response of the system from the different control techniques. It has been found that the performance of PIDSMC is better than conventional PID technique. The transient of PIDSMC technique can be settles down after $3.3 \mathrm{sec}$ while the response from the PID has large overshoot and settles down after $5.2 \mathrm{sec}$. Notice, that the performance of the PIDSMC with an adopted low-pass filter is better than the conventional PID and the PIDSMC techniques. The response from the proposed technique has tiny transient state which its response can be approach to steady state after $1.7 \mathrm{sec}$. Note that these techniques have equivalent parameters.

For their control input signal, the PIDSMC input signal is smaller than the PID as illustrated Fig. 5 while the residual of error in term of uncertainty as shown in Fig. 6 behave in the same manner. This means that the response of the PIDSMC can be reached to the desired state faster than the PID due to the sliding function $\mathrm{s}(\mathrm{t})$ of the PIDSMC is close to 0 more than the conventional PID.

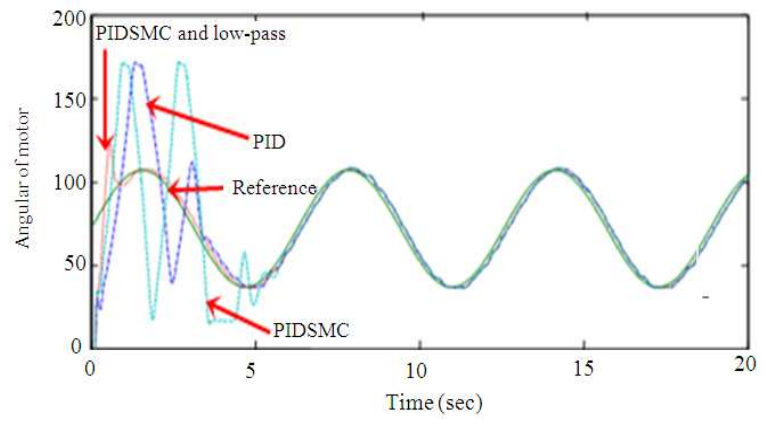

Fig. 4: Angular displacement of the motor by PID, PIDSMC and PIDSMC with low-pass filter.

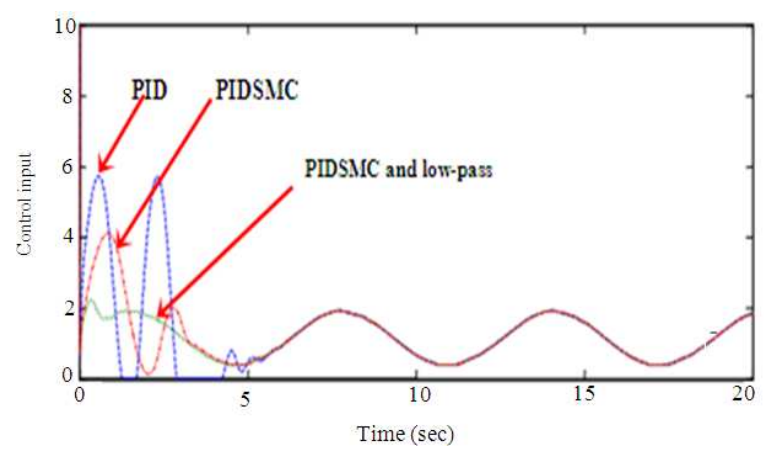

Fig. 5: Control input of PID, PIDSMC and PIDSMC with low-pass filter 


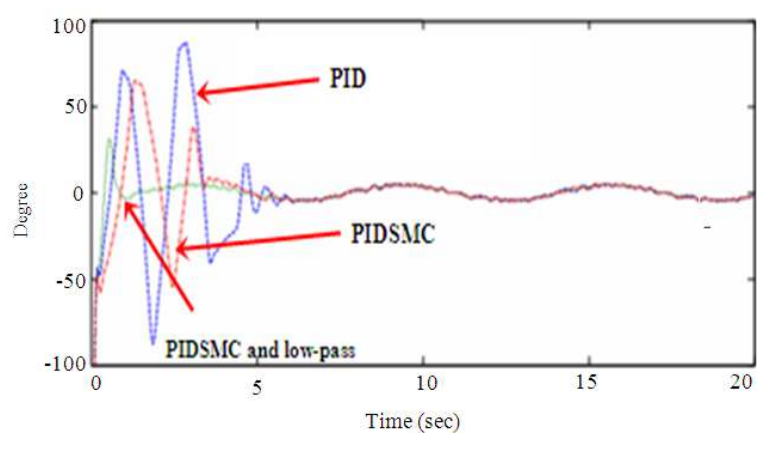

Fig. 6: Residual error in term of uncertainty signal of PID, PIDSMC and PIDSMC with low-pass filter

Obviously, the performance of the proposed control technique is better than the PID and PIDSMC. This is because the proposed technique have stability to recovers the disturbance in small time due to the derivative effect has been alleviated by the low-pass filter. Refers to the experimental results in Fig. 4-6, the residual error signal has smaller overshoot or oscillation than the PID and PIDSMC. According to the experimental results, the proposed technique can confirm the actual implementation with high precision.

Note that large overshoot at the initial state occur from the initial error and the gain of the controller which is learned from the convergence rate of the system response. Too large values of the learning gains can deteriorate the good transient response of the system. Therefore any suitable parameters should be adjusted by understanding of the PID gain adjustment.

The behavior of a PID gain tuning can be characterized in terms of its frequency response where the gain increases with frequency. This is because the nature of the derivative function in the PID that it is likely to cause problem in any noisy system. In fact, all high-frequency noise is amplified by term of the derivative. Further intensification of an error will damage a control system. This is why digital controllers will almost never implement a pure derivative. And if the rate of process variable cannot be fed back directly, this problem can be solve by modifying the PID tuning so that the gain curve levels off beyond a given frequency. To limit the system frequency response, a controller has to limit the amplification of the noise. The modified technique essentially consists of a PID tuning followed by a low-pass filter in conjunction with the differentiator to attenuate noise (Jacob, 2000). The result of incorporated a low-pass filter in all PID junction (Fig. 1) shown in Fig. 4. It has been found that the transient response can be reduced at initial state. The response settles down after $1.7 \mathrm{sec}$ and $\mathrm{s} \rightarrow 0$ faster than the other techniques.

\section{CONCLUSION}

This study presented incorporation between a PID tuning and sliding mode control with an adopted lowpass filter for a position tracking control of a DC servo motors. The nonlinear uncertain servo motor system has been steered to desire position by virtue of sliding mode control and the high frequency chattering was eliminated by the boundary layer technique. The task of the PID is to perform when $s(t) \neq 0$ while the equivalent control input is described when the trajectory is nearly $\mathrm{s}(\mathrm{t})=0$. Moreover, a low-pass filter has been adopted in order to limit the amplification of the noise that may occur from derivative portion in the PID.

From the experimental results, the proposed technique has good tracking performance and it has the transient behavior at initial state better than the conventional PID and the PIDSMC.

However, the controller strongly depends on the specified parameters in the designing control function. Therefore, any self tuning for the control parameter should be studied in the future.

\section{ACKNOWLEDGEMENT}

The authors would like to acknowledge the Department of Industrial Engineering and Department of Mechanical Engineering, Khon Kaen University, Thailand for their financial and equipment supports.

\section{REFERENCES}

Barmish, B. and G. Leitmann, 1982. On ultimate boundedness control of uncertain systems in the absence of matching assumptions. IEEE Trans. Automatic Control, 27: 153-158. http://ieeexplore.ieee.org/xpl/freeabs_all.jsp?arnum ber $=1102862$

Chang, W.D. and J.J. Yan, 2005. Adaptive robust PID controller design based on a sliding mode for uncertain chaotic systems. Chaos Solitions Fract, 26: 167-175. DOI: 10.1016/j.chaos.2004.12.013

Coddington, E.A. and N. Levison, 1984. Theory of Ordinary Differential Equation. Krieger Pub Co., ISBN: 10: 0898747554, pp: 429.

Corless, M. and G. Leitmann, 1981. Continuous state feedback guaranteeing uniform ultimate boundedness for uncertain dynamic systems. IEEE Trans. Automatic Control, 26: 1139-1144. http://ieeexplore.ieee.org/xpl/freeabs_all.jsp?arnum ber $=1102785$ 
Decarlo, R.A., S.H. Zak and G.P. Matthews, 1988. Variable structure control of nonlinear multivariable systems. A Tutor. Proc. IEEE, 76: 212-232. DOI: $10.1109 / 5.4400$

Fujisawa, S. and K. Kawada, 2004. Speed Control of 3mass System with Sliding mode control and CMAC. Proceeding of the IEEE Conference on Systems, Man and Cybernetics, Oct. 10-13, IEEE Xplore Press, USA., pp: 4400- 4407. DOI: 10.1109/ICSMC.2004.1401224

Jafarov, E.M., M.N.A. Parlakci and Y. Istefano- Pulos, 2005. A new variable structure PID-controller design for robot manipulators. IEEE Trans, Control Syst. Technol., 13: 122-130. DOI: 10.1109/TCST.2004.838558

Jacob, T., 2000. Advanced Compensation Tools. Galil Motion, Control Inc., Mountain View, Calif, pp: 40-41.

Kelly, R. and J. Moreno, 2001. Learning PID structures in an introductory course of automatic control. IEEE Trans. Educ., 44: 373-376. DOI: 10.1109/13.965786

Utkin, V.I., 1978. Sliding Modes and their Application in Variable Structure Systems. MIR Publishers, Moscow, pp: 9-38.
Moradi, M.H., 2003. New techniques for PID controller design. Proceeding of the IEEE Conference on Control Applications, June 23-25, IEEE Xplore Press, USA., pp: 903-908. DOI: 10.1109/CCA.2003.1223130

Radpukdee, T. and P. Jirawattana, 2008. Uncertainty learning and compensation: An application to pressure tracking of an electro-hydraulic proportional relief valve. Control Eng. Pract., 17: 291-301. DOI: 10.1016/j.conengprac.2008.07.008

Slotine, J.J.E. and W. Li, 1991. Applied Nonlinear Control. Prentice-Hall International, Inc., New Jersey, ISBN: 10: 0130408905, pp: 461.

Wai, R.J., C.M. Lin and C.F. Hsu, 2004. Adaptive fuzzy Sliding mode control for electrical servo drive. Fuzzy Sets Syst., 143: 295-310. http://cat.inist.fr/?aModele $=$ afficheN\&cpsidt $=1560$ 3475

Xu, J.X. and D. Huang, 2007. Optimal tuning of PID parameters using iterative learning approach. Proceeding of the IEEE 22nd International Symposium on Intelligent Control, Oct. 1-3, IEEE Xplore Press, Singapore, pp: 226-231. DOI: 10.1109/ISIC.2007.4450889 